\title{
Posterior corrective surgery with a multilevel transforaminal lumbar interbody fusion and a rod rotation maneuver for patients with degenerative lumbar kyphoscoliosis
}

\author{
Akira Matsumura, MD, ${ }^{1}$ Takashi Namikawa, MD, ${ }^{1}$ Minori Kato, MD, ${ }^{1}$ Tomonori Ozaki, MD, \\ Yusuke Hori, MD, ${ }^{1}$ Noriaki Hidaka, MD, ${ }^{1}$ and Hiroaki Nakamura, MD² \\ 'Department of Orthopaedic Surgery, Osaka City General Hospital; and 'Department of Orthopaedic Surgery, Osaka City \\ University Graduate School of Medicine, Osaka, Japan
}

\begin{abstract}
The purpose of this study was to assess the clinical results of posterior corrective surgery using a multilevel transforaminal lumbar interbody fusion (TLIF) with a rod rotation (RR) and to evaluate the segmental corrective effect of a TLIF using CT imaging. The medical records of 15 consecutive patients with degenerative lumbar kyphoscoliosis (DLKS) who had undergone posterior spinal corrective surgery using a multilevel TLIF with an RR technique and who had a minimum follow-up of 2 years were retrospectively reviewed. Radiographic parameters were evaluated using plain radiographs, and segmental correction was evaluated using CT imaging. Clinical outcomes were evaluated with the Scoliosis Research Society Patient Questionnaire-22 (SRS-22) and the SF-36.
\end{abstract}

The mean follow-up period was 46.7 months, and the mean age at the time of surgery was 60.7 years. The mean total SRS-22 score was 2.9 before surgery and significantly improved to 4.0 at the latest follow-up. The physical functioning, role functioning (physical), and social functioning subcategories of the SF- 36 were generally improved at the latest follow-up, although the changes in these scores were not statistically significant. The bodily pain, vitality, and mental health subcategories were significantly improved at the latest follow-up $(p<0.05)$.

Three complications occurred in 3 patients (20\%). The Cobb angle of the lumbar curve was reduced to $20.3^{\circ}$ after surgery. The overall correction rate was $66.4 \%$. The pelvic incidence-lumbar lordosis (preoperative/postoperative $=$ $\left.31.5^{\circ} / 4.3^{\circ}\right)$, pelvic tilt $\left(29.2^{\circ} / 18.9^{\circ}\right)$, and sagittal vertical axis $(78.3 / 27.6 \mathrm{~mm})$ were improved after surgery and remained so throughout the follow-up. Computed tomography image analysis suggested that a 1-level TLIF can result in $10.9^{\circ}$ of scoliosis correction and $6.8^{\circ}$ of lordosis.

Posterior corrective surgery using a multilevel TLIF with an RR on patients with DLKS can provide effective correction in the coronal plane but allows only limited sagittal correction.

https://thejns.org/doi/abs/10.3171/2016.7.SPINE16172

KEY WORDS multilevel transforaminal lumbar interbody fusion; rod rotation maneuver; degenerative lumbar kyphoscoliosis; surgical outcomes

$\mathrm{D}$ EGENERATIVE lumbar kyphoscoliosis (DLKS) is classified based on the etiology of the scoliosis. Aebi ${ }^{1}$ categorized adult scoliosis into 3 subtypes: primary degenerative scoliosis (de novo scoliosis), progressive idiopathic scoliosis, and secondary degenera- tive scoliosis. Simmons ${ }^{21}$ based his classification of adult scoliosis on the presence or absence of preexisting spine changes. These 2 authors recommended corrective surgery for patients with DLKS who show evidence of spinal imbalance. The surgical aims of corrective surgery are to im-

\footnotetext{
ABBREVIATIONS ASD = adult spinal deformity; CVA = coronal vertical axis; DLKS = degenerative lumbar kyphoscoliosis; FBB = fulcrum backward bending; IVR = intervertebral release; L-Cobb angle = Cobb angle of lumbar curve; LIV = lowest instrumented vertebra; $L L=$ lumbar lordosis; MPR = multiplanar reconstruction; PO = 1 week after surgery; PreO = immediately prior to surgery; $\mathrm{PI}=$ pelvic incidence; $\mathrm{PT}$ = pelvic tilt; $\mathrm{RR}$ = rod rotation; SLA = segmental lordotic angle; SRS-22 = Scoliosis Research Society Patient Questionnaire-22; SVA = sagittal vertical axis; SWA = scoliotic wedging angle; T-Cobb angle = Cobb angle of compensatory thoracic curve; TK = thoracic kyphosis; TLIF = transforaminal lumbar interbody fusion; TLK = thoracolumbar kyphosis; UIV = upper instrumented vertebra.
}

SUBMITTED February 8, 2016. ACCEPTED July 18, 2016.

INCLUDE WHEN CITING Published online October 7, 2016; DOI: 10.3171/2016.7.SPINE16172. 
prove spinal alignment and balance and to relieve pain and functional symptoms. Patients with DLKS often present with $3 \mathrm{D}$ rigid curvatures that can be accelerated by disc degeneration and osteophyte formation. Many DLKS patients also have osteoporotic vertebrae. The intervertebral release (IVR) of all 3 columns, the degenerated disc, osteophytes, and the degenerated facet joints, are absolutely necessary when these patients undergo spinal deformity correction.

Traditionally, rigid lumbar curves that are treated with an anterior release and posterior instrumented fusion require 2 separate approaches. Despite the ability to perform an extended release, anterior approaches have obvious disadvantages, including a prolonged operative time and potential morbidities such as vascular injury, ureteral damage, ileus, and retrograde ejaculation. ${ }^{10,14}$ Posterior lumbar interbody fusion (PLIF), which was first described by Cloward, ${ }^{7}$ can provide adequate neural decompression and segmental stability. The advantages of transforaminal lumber interbody fusion (TLIF) in adult deformity surgery include technical simplicity, a shorter operative time, and the need for only a single approach.

Corrective surgery for adolescent idiopathic scoliosis with Cotrel-Dubousset instrumentation initially resulted in $3 \mathrm{D}$ correction. ${ }^{8} \mathrm{~A}$ rod rotation (RR) maneuver allows the frontal scoliotic deformity to be converted into a "normal" sagittal thoracic kyphosis (TK) or lumbar lordosis (LL). In DLKS, an IVR with the TLIF of several segments and an RR may provide good 3D correction. To our knowledge, little is known about the outcomes of posterior corrective surgery involving multilevel TLIF and RR in patients with DLKS. This study was performed to assess the clinical results of such procedures.

\section{Methods}

Since 2009, at a single institute, one surgeon surgically treated 19 DLKS patients whose Cobb angles were more than $45^{\circ}$. Four patients who underwent 3-column osteotomy including posterior vertebral column resection or pedicle subtraction osteotomy were excluded from this study. Thus, we retrospectively reviewed the medical records of 15 patients with DLKS who had undergone posterior corrective surgery involving a multilevel TLIF and an RR maneuver and who had at least a 2-year follow-up period. The mean age at surgery was 61.0 years (range 42-77 years), and the average follow-up period was 46.7 months (range 24-78 months). All patients were female. Eight of the 15 patients had earlier been diagnosed with adolescent idiopathic scoliosis; however, none of them had undergone surgical intervention. Five of the 8 patients demonstrated 2 or 3 fused vertebrae on the plain radiographs. All patients complained of multiple years of low-back pain that could not be improved with any conservative treatments. Eight of the 15 patients also complained of leg pain and neurogenic intermittent claudication due to spinal canal stenosis. The following radiographic parameters were assessed with standing anteroposterior and lateral radiographs immediately prior to surgery (PreO), 1 week after surgery (PO), and at the most recent follow-up: the Cobb angle of the lumbar curve (L-Cobb angle) and compensa- tory thoracic curve (T-Cobb angle), the coronal vertical axis (CVA), the degree of TK (T5-12), the degree of thoracolumbar kyphosis (TLK; T10-L2), the degree of LL (T12-S1), pelvic tilt (PT), and pelvic incidence (PI). We also evaluated each patient's curve flexibility in the coronal plane with side bending films and in the sagittal plane with fulcrum backward bending (FBB) films. ${ }^{6}$ All patients underwent multiplanar reconstruction (MPR) CT imaging at the $\mathrm{PreO}$ and $\mathrm{PO}$ time points. Comparing the $\mathrm{PreO}$ and PO CT images, we measured the scoliotic wedging angle (SWA) in the coronal plane and the segmental lordotic angle (SLA) in the sagittal plane to evaluate the effect of the IVR of the TLIF (Fig. 1).

We evaluated clinical outcomes with the Japanese editions of the Scoliosis Research Society Patient Questionnaire-22 (SRS-22) and the SF-36 administered PreO and at the latest follow-up. All data were analyzed statistically using an ANOVA, the Mann-Whitney U-test, or a paired or unpaired t-test as appropriate (JMP version 11, SAS Institute). The level of significance for all tests was defined as $\mathrm{p}<0.05$.

\section{Surgical Procedures}

Prior to the multilevel TLIF, pedicle screws should be placed into all fused segments. We performed a Grade 1 or Grade 2 osteotomy ${ }^{18}$ on all segments except for those that were used in the TLIF. A 3- or 4-level TLIF should be necessary for all DLKS patients. An L4-5 or L5-S1 TLIF is performed using a unilateral approach, as previously described by Teneichi et al. ${ }^{25}$ Preserving the facet on the contralateral side can provide a larger bone grafting space. A 2-level IVR using a bilateral approach is then performed around the apex of the scoliotic curvature. After a bilateral facetectomy, a discectomy from the convex side is performed. Then the concave side of the deformity is addressed. Releasing the osteophyte that completely connects the cranial and the caudal vertebrae is sometimes necessary. We first made a notch in the osteophyte using a chisel and then completed the release using a spreader (Fig. 2). Following the 2-level IVR and the 1-level TLIF, a temporary rod is applied to the convex side of the deformity from T-12 to L-5. With the temporary rod, an RR maneuver can be performed. We then placed the intervertebral cages into the segments around the deformity apex that had been completely released. Lastly, a final rod is applied to the concave side of the deformity. Operative procedures are summarized in Fig. 3.

\section{Results}

\section{Surgical Outcomes and Surgical Data}

The averaged operative time was 511.7 minutes (range 420-720 minutes). The mean blood loss during surgery was $1752.5 \mathrm{ml}$ (range 820-2600 ml). The upper instrumented vertebra (UIV) was T-9 for 6 patients and T-10 for 9 patients. L-5 was selected as the lowest instrumented vertebra (LIV) for 5 patients (Fig. 4), and 10 patients underwent spinopelvic fixation (Fig. 5). The averaged number of fused vertebrae was 8.1 (range 7-9). A 3-level TLIF was performed on 13 patients, and a 4-level TLIF was 

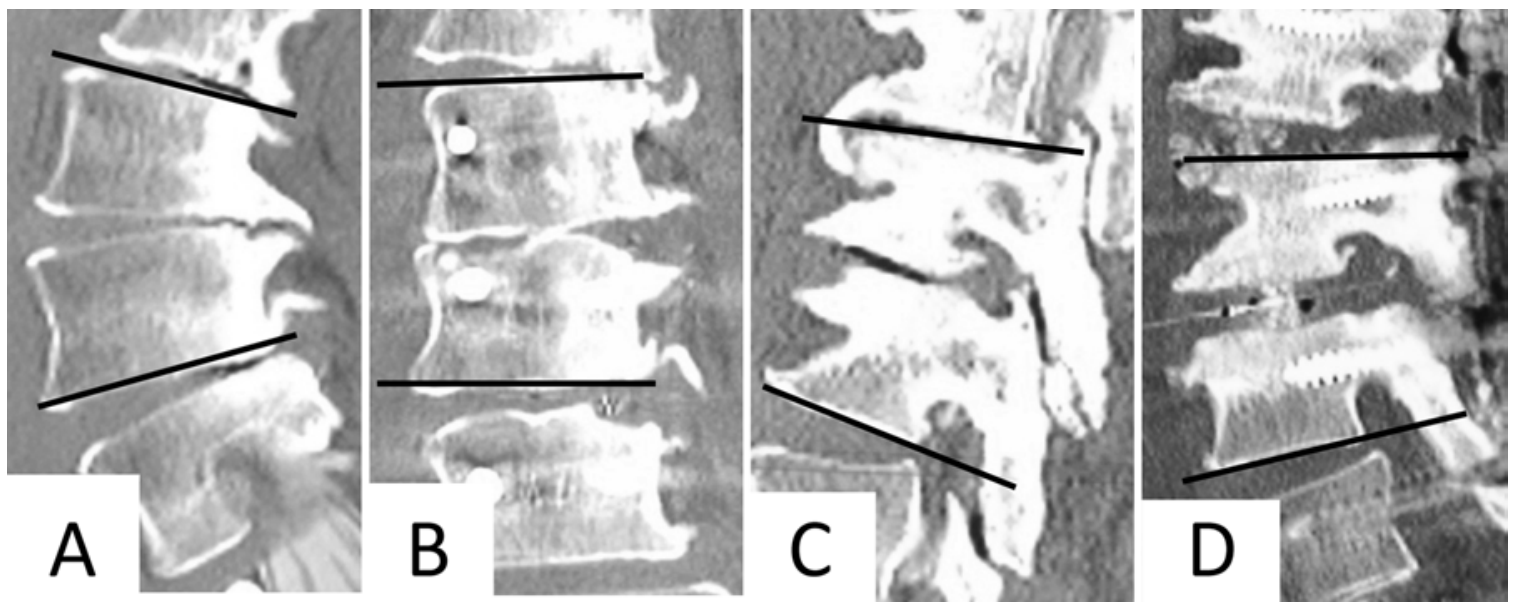

FIG. 1. Evaluation of the impact of a TLIF using MPR CT images. The SWA is indicated by the angle created by the intersection of the black lines. Improvement in the SWA was measured in the coronal views at the PreO (A) and PO (B) time points. Improvement in the SLA was measured in sagittal views at the PreO (C) and PO (D) time points.

performed on 2 patients. Overall, there were 3 complications in 3 patients (20\%). Two of these complications were associated with surgery and consisted of 1 dural tear and 1 misplaced pedicle screw. Neither case resulted in any adverse sequelae. However, additional surgery time was needed to change the pedicle screws. No early complications such as a neurological deficit, infection, or epidural hematoma were observed. One patient had a UIV fracture, although it was asymptomatic and did not lead to proximal junctional kyphosis.
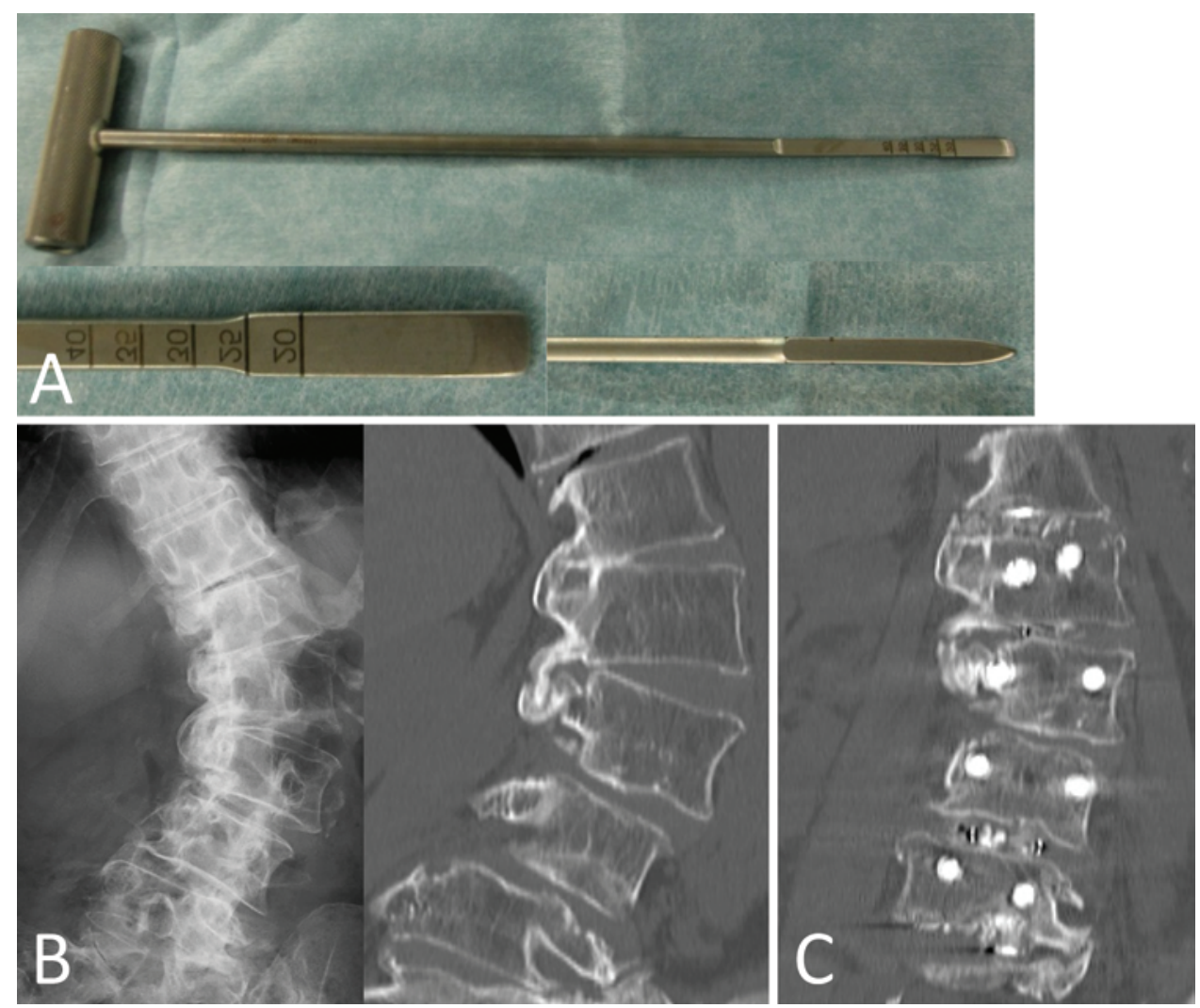

FIG. 2. The operative maneuver for osteophyte release. Photograph of a disc spreader (Stryker Japan K.K., A). Preoperative radiograph (B, left) and coronal MPR CT image $(\mathbf{B}$, right), the latter showing what appears to be bony bridging among the 3 vertebrae. Postoperative CT image (C) showing that complete release of the osteophyte provides adequate IVR. Figure is available in color online only. 


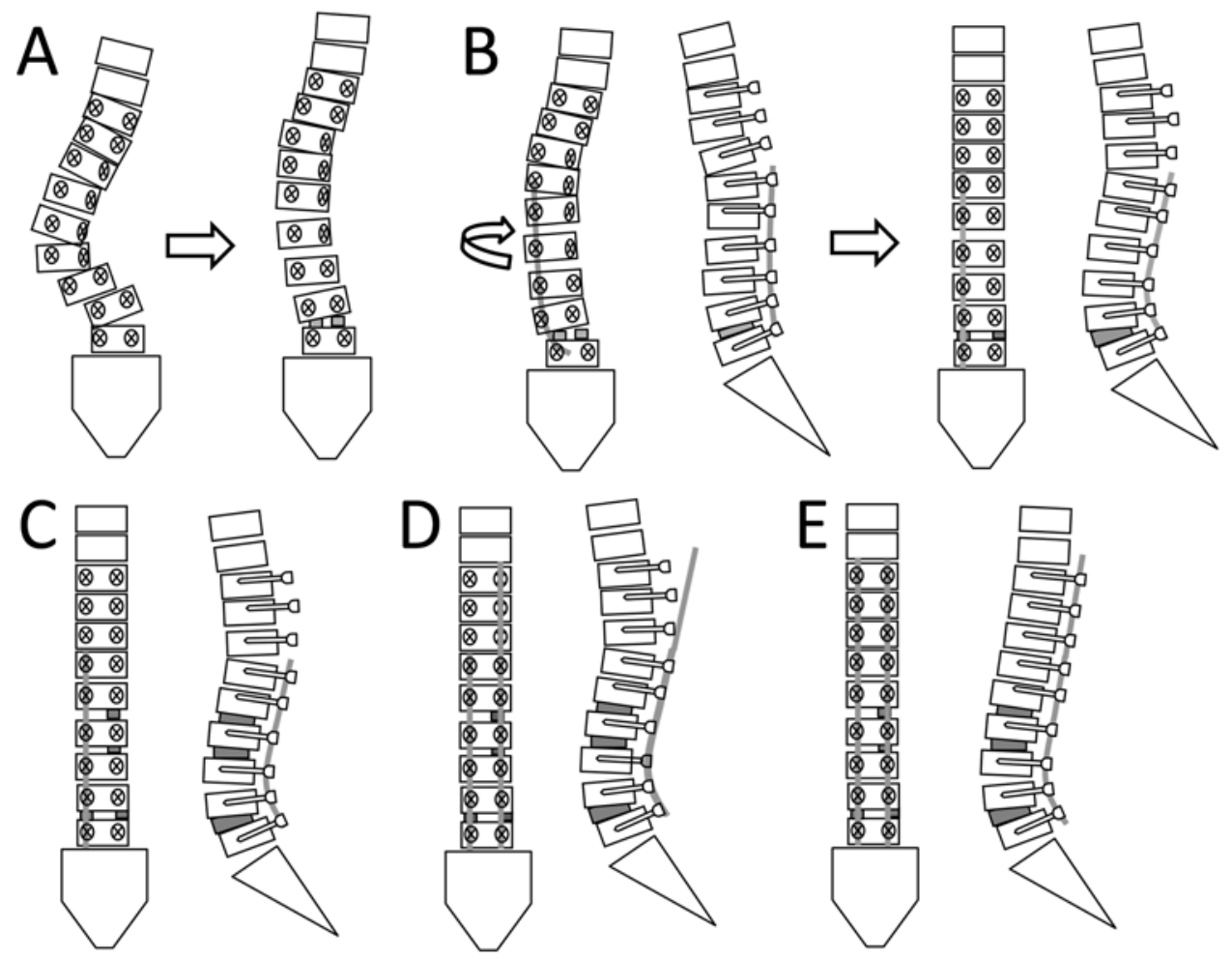

FIG. 3. Summary of operative procedures. A: Pedicle screws are placed into all fused segments. An L4-5 TLIF and 2-level IVR $(\mathrm{L} 1-3)$ are performed. B: A temporary rod $(6.0-\mathrm{mm}$ titanium alloy rod) is applied to the convex side of the deformity from T-12 to L-5. With the temporary rod, an RR maneuver is performed. C: We then placed intervertebral cages into L1-3, which had been released completely. D: A final rod is applied to the concave side of the deformity. E: The temporary rod is changed to a final rod on the convex side as well.
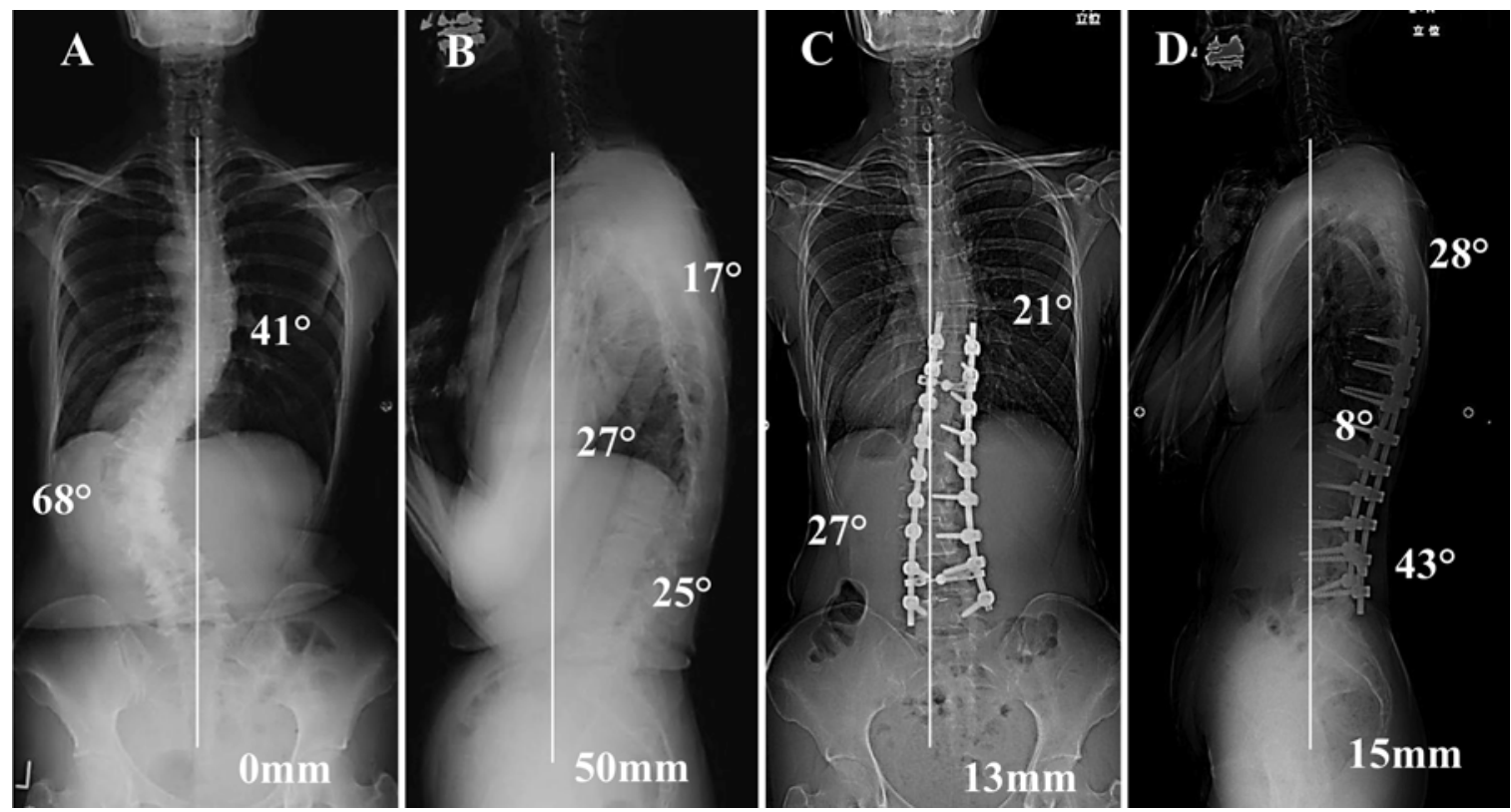

FIG. 4. Case 1. A 52-year-old female, who had a history of adolescent idiopathic scoliosis treated with a brace, underwent T9-L5 posterior corrective surgery using an L1-3 and L4-5 TLIF. The preoperative anteroposterior radiograph (A) shows that the L-Cobb and the T-Cobb angles were $68^{\circ}$ and $41^{\circ}$, respectively. The preoperative lateral radiograph (B) shows a TK of $17^{\circ}$, TLK of $27^{\circ}$, $\mathrm{LL}$ of $25^{\circ}, \mathrm{PT}$ of $28^{\circ}$, and $\mathrm{PI}$ of $55^{\circ}$. The PI-LL was calculated to be $30^{\circ}$. The 5 -year postoperative anteroposterior radiograph (C) shows T-Cobb and L-Cobb angles reduced to $21^{\circ}$ and $27^{\circ}$, respectively. The SVA shifted $50 \mathrm{~mm}$ anteriorly. The 5 -year postoperative lateral radiograph (D) showed a TK of $28^{\circ}$, TLK of $8^{\circ}, \mathrm{LL}$ of $43^{\circ}$, and PT of $20^{\circ}$. The PI-LL was reduced to $10^{\circ}$, and the SVA improved to $15 \mathrm{~mm}$. 

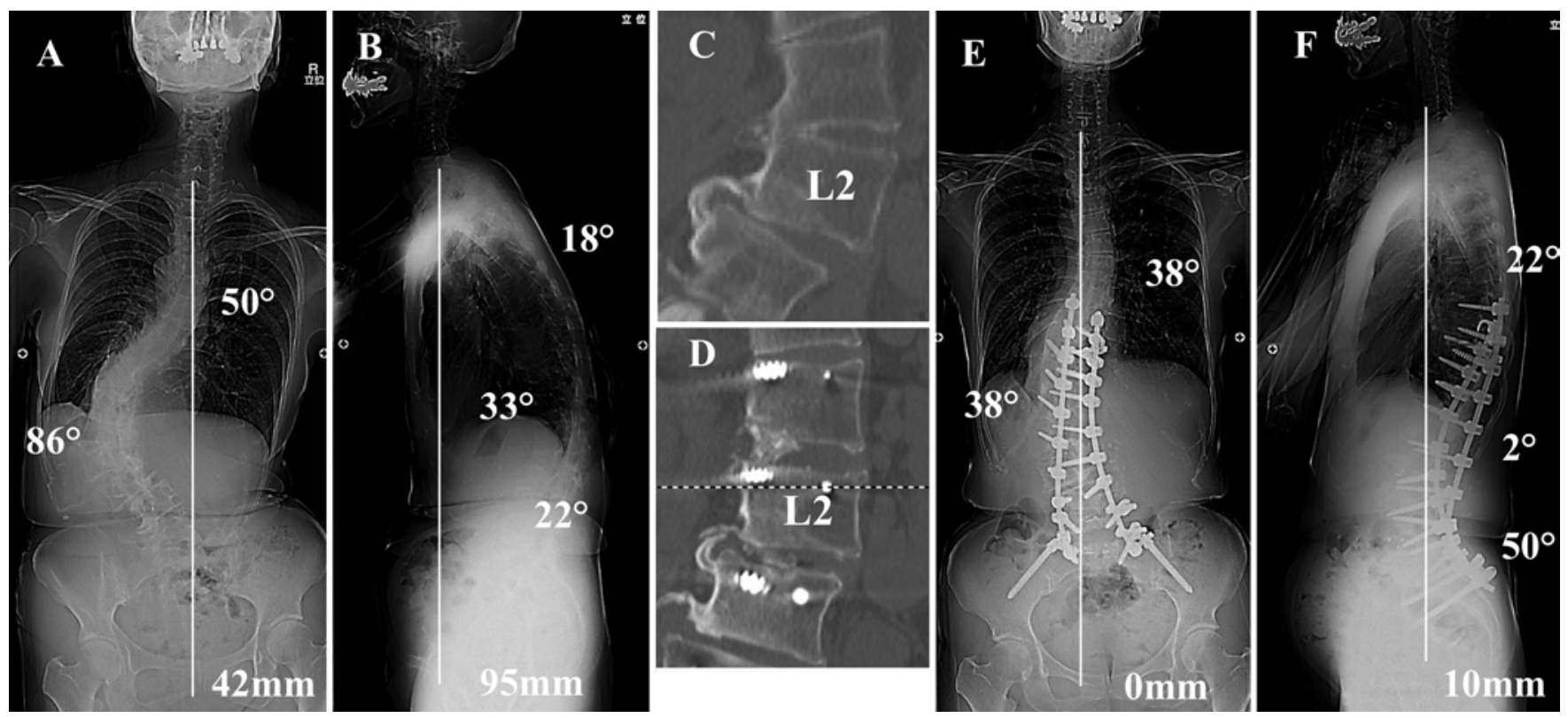

FIG. 5. Case 2. A 56-year-old female, who had a history of adolescent idiopathic scoliosis treated with a brace, underwent T9-pelvis posterior corrective surgery using an L1-2, L2-3, L4-5, and L5-S1 TLIF. Preoperative anteroposterior radiograph (A) showed that the L-Cobb and T-Cobb angles were $85^{\circ}$ and $50^{\circ}$, respectively. Preoperative lateral radiograph (B) showed a TK of $18^{\circ}$, TLK of $33^{\circ}$, LL of $22^{\circ}$, PT of $30^{\circ}$, and PI of $53^{\circ}$. The PI-LL was calculated to be $28^{\circ}$. The SVA shifted $95 \mathrm{~mm}$ anteriorly. Preoperative CT scan (C) showed a spontaneous fusion from L-1 to L-3. Postoperative CT scan (D) showing complete release of the deformity using a TLIF. A 3-year postoperative radiograph (E) shows a Cobb angle of the compensatory thoracic and lumbar deformities reduced to $38^{\circ}$ and $38^{\circ}$, respectively. A 3-year postoperative lateral radiograph (F) showed a TK of $22^{\circ}$, TLK of $2^{\circ}$, LL of $50^{\circ}$, and PT of $10^{\circ}$. The PI-LL was reduced to $5^{\circ}$, and the SVA improved to $10 \mathrm{~mm}$.

The mean total SRS-22 scores were $2.9 \pm 0.87$ prior to surgery. This mean score significantly improved to $4.0 \pm$ 0.56 at the latest follow-up ( $<0.0001)$. The overall patient satisfaction scores were 4.4 (range 3.5-5.0), which indicated a good surgical outcome. All the domains of the SRS-22 score significantly improved and are shown in Table 1 . Health-related quality of life data measured using the SF-36 are shown in Table 2. The physical functioning, role functioning (physical), and social functioning subcategories of the SF-36 were generally improved at the latest follow-up, although the changes in these scores were not statistically significant. The bodily pain, vitality, and mental health subcategories were significantly improved at the time of the latest follow-up ( $\mathrm{p}<0.05)$.

\section{Radiographic Evaluation}

The mean values of the preoperative radiographic parameters were as follows: L-Cobb angle 59.3 ${ }^{\circ}$, T-Cobb angle $31.7^{\circ}$, TK $15.5^{\circ}$, TLK $17.3^{\circ}$, LL $20.9^{\circ}$, PT $29.2^{\circ}$, PI $52.3^{\circ}$, CVA $37.4 \mathrm{~mm}$, and sagittal vertical axis (SVA) 78.3 $\mathrm{mm}$. The preoperative mean PI-LL was $31.5^{\circ}$. Based on the SRS-Schwab adult spinal deformity (ASD) classification, ${ }^{20}$ 7 patients had an L coronal curve type, and 8 patients had a D coronal curve type. The sagittal modifiers are summarized in Table 2. In bending films, the L-Cobb and TCobb angles were reduced to $40.2^{\circ}$ and $18.4^{\circ}$, respectively. The LL increased to $38.2^{\circ}$ based on FBB films. The PI-LL (FBB) was $14.1^{\circ}$ (range $-7^{\circ}$ to $29^{\circ}$ ). The L-Cobb angle was reduced to $20.3^{\circ}$ at the $\mathrm{PO}$ time point and was maintained at $20.7^{\circ}$ at the most recent follow-up. The overall correc- tion rate was $66.4 \%$. The PI-LL was reduced to $4.3^{\circ}$ after surgery. The PT improved to $18.9^{\circ}$ at the PO time point, which persisted throughout the follow-up. The SVA also improved to $27.6 \mathrm{~mm}$ at the $\mathrm{PO}$ time point, which persisted throughout the follow-up. Radiographic parameters are summarized in Tables 3 and 4.

\section{TABLE 1. Surgical outcome data}

\begin{tabular}{lccc}
\hline \multicolumn{1}{c}{ Survey } & PreO & Latest FU & p Value \\
\hline SSR-22 & & & \\
\hline Function/activity & 3.3 & 4.3 & 0.38 \\
\hline Pain & 3.3 & 4.0 & 0.50 \\
\hline Self-image & 2.2 & 4.0 & 0.03 \\
\hline Mental health & 3.6 & 4.2 & 0.21 \\
\hline Total score & 2.87 & 4.00 & $<0.0001$ \\
\hline Satisfaction & - & 4.3 & - \\
\hline SF-36 & & & \\
\hline Physical functioning & 53.3 & 71.6 & 0.072 \\
\hline Physical role functioning & 58.5 & 79.2 & 0.074 \\
\hline Bodily pain & 37.3 & 69.5 & $<0.0001$ \\
\hline General health & 54.7 & 60.2 & 0.50 \\
\hline Vitality & 48.8 & 63.4 & 0.054 \\
\hline Social functioning & 67.5 & 84.2 & 0.080 \\
\hline Emotional role functioning & 71.1 & 83.9 & 0.143 \\
\hline Mental health & 61.3 & 77 & 0.011 \\
\hline
\end{tabular}

$\mathrm{FU}=$ follow-up. 
TABLE 2. Patient spinal deformity based on the SRS-Schwab ASD classification

\begin{tabular}{cc}
\hline Parameter & No. of Cases \\
\hline Coronal curve type & \\
\hline T: thoracic only & 0 \\
\hline TL/L: lumbar only & 7 \\
\hline D: double curve & 8 \\
\hline N: no major coronal deformity & 0 \\
\hline Sagittal modifiers & \\
\hline PI-LL & 1 \\
\hline$<10^{\circ}$ & 2 \\
\hline $10^{\circ}-20^{\circ}$ & 12 \\
\hline$>20^{\circ}$ & \\
\hline Global alignment: SVA & 4 \\
\hline$<40 \mathrm{~mm}$ & 3 \\
\hline $40-90 \mathrm{~mm}$ & 8 \\
\hline$>95 \mathrm{~mm}$ & 1 \\
\hline $\mathrm{PT}$ & 7 \\
\hline$<20^{\circ}$ & 7 \\
\hline $10^{\circ}-20^{\circ}$ & \\
\hline$<30^{\circ}$ & \\
\hline
\end{tabular}

Preoperative MPR CT images showed the spontaneous fusion of 2 or 3 vertebrae in the 5 patients. The mean SWA and SLA before surgery were $15.4^{\circ}$ and $5.6^{\circ}$, which improved to $4.5^{\circ}$ and $12.5^{\circ}$ after surgery, respectively. The MPR CT data are shown in Table 5.

\section{Discussion}

The viability of corrective surgery for ASD continues to be an important topic of discussion. However, the surgical interventions for ASD are inconsistent because of

TABLE 3. Postoperative and long-term follow-up changes to radiographic measurements made in the coronal plane

\begin{tabular}{lccc}
\hline Parameter & PreO & PO & Latest FU \\
\hline $\begin{array}{c}\text { T-Cobb angle } \\
\text { (range) }\end{array}$ & $31.7^{\circ}\left(10^{\circ}-50^{\circ}\right)$ & $19.3^{\circ}\left(5^{\circ}-38^{\circ}\right)$ & $18.0^{\circ}\left(5^{\circ}-38^{\circ}\right)$ \\
\hline$p$ Value & & 0.021 & 0.79 \\
\hline $\begin{array}{l}\text { T-Cobb on } \\
\text { bending } \\
\text { films (range) }\end{array}$ & $18.4^{\circ}\left(0-41^{\circ}\right)$ & & \\
\hline $\begin{array}{l}\text { L-Cobb angle } \\
\text { (range) }\end{array}$ & $59.3^{\circ}\left(45^{\circ}-86^{\circ}\right)$ & $20.3^{\circ}\left(10^{\circ}-40^{\circ}\right)$ & $20.7^{\circ}\left(10^{\circ}-41^{\circ}\right)$ \\
\hline $\begin{array}{l}p \text { Value } \\
\text { L-Cobb on } \\
\text { bending } \\
\text { films (range) }\end{array}$ & $40.2^{\circ}\left(20^{\circ}-77^{\circ}\right)$ & $<0.0001$ & 0.91 \\
\hline $\begin{array}{l}\text { CVA in mm } \\
\text { (range) }\end{array}$ & $37.4(0-60)$ & $22.7(0-34)$ & $10.1(0-30)$ \\
\hline$p$ Value & & 0.17 & 0.25 \\
\hline
\end{tabular}

TABLE 4. Postoperative and long-term follow-up changes to radiographic measurements made in the sagittal plane

\begin{tabular}{|c|c|c|c|}
\hline Parameter & PreO & PO & Latest FU \\
\hline TK (range) & $15.5^{\circ}\left(-10^{\circ}\right.$ to $\left.40^{\circ}\right)$ & $22.9^{\circ}\left(5^{\circ}-36^{\circ}\right)$ & $25.9^{\circ}\left(5^{\circ}-36^{\circ}\right)$ \\
\hline$p$ Value & & 0.048 & 0.544 \\
\hline $\begin{array}{l}\text { TLK } \\
\text { (range) }\end{array}$ & $17.3^{\circ}\left(-18^{\circ}\right.$ to $\left.43^{\circ}\right)$ & $4.4^{\circ}\left(-6^{\circ}\right.$ to $\left.12^{\circ}\right)$ & $4.3^{\circ}\left(-7^{\circ}\right.$ to $\left.14^{\circ}\right)$ \\
\hline$p$ Value & & 0.015 & 0.859 \\
\hline LL (range) & $20.9^{\circ}\left(-9^{\circ}\right.$ to $\left.43^{\circ}\right)$ & $46.9^{\circ}\left(37^{\circ}-59^{\circ}\right)$ & $45.4^{\circ}\left(35^{\circ}-58^{\circ}\right)$ \\
\hline$p$ Value & & 0.0001 & 0.508 \\
\hline $\begin{array}{l}\text { LL on } \\
\text { FBB }\end{array}$ & $38.2^{\circ}\left(20^{\circ}-67^{\circ}\right)$ & & \\
\hline $\mathrm{PT}$ (range) & $29.2^{\circ}\left(18^{\circ}-49^{\circ}\right)$ & $18.9^{\circ}\left(14^{\circ}-26^{\circ}\right)$ & $18.8^{\circ}\left(14^{\circ}-26^{\circ}\right)$ \\
\hline$p$ Value & & 0.004 & 0.714 \\
\hline $\mathrm{PI}$ & $52.3^{\circ}\left(43^{\circ}-65^{\circ}\right)$ & - & - \\
\hline PI-LL & $31.5^{\circ}\left(8^{\circ}-59^{\circ}\right)$ & $4.3^{\circ}\left(-6^{\circ}\right.$ to $\left.11^{\circ}\right)$ & $5.4^{\circ}\left(-6^{\circ}\right.$ to $\left.11^{\circ}\right)$ \\
\hline$p$ Value & & $<0.0001$ & 0.51 \\
\hline $\begin{array}{l}\text { PI-LL } \\
\quad(F B B)\end{array}$ & $14.1^{\circ}\left(-7^{\circ}\right.$ to $\left.29^{\circ}\right)$ & & \\
\hline $\begin{array}{c}\text { SVA in } \\
\mathrm{mm}\end{array}$ & $78.3(10-135)$ & 27.6 (-5 to 70$)$ & $27.5(0-80)$ \\
\hline$p$ Value & & 0.007 & 0.948 \\
\hline
\end{tabular}

the comorbidities typically seen in these patients. Many ASD patients have poor bone quality due to osteoporosis, which makes spinal instrumentation and correction more difficult. ${ }^{24,26,27}$ Degenerative changes to the disc and facet joints, ${ }^{1,12,21}$ along with spinal stenosis ${ }^{15}$ that leads to a more rigid spine, further complicate surgery. A long operative time in the prone position and significant blood loss predispose patients to postoperative complications. Rates of complications after ASD correction have been reported to be about $20 \%-40 \% .^{5,17}$ Therefore, we should only treat ASD patients after a meticulous evaluation of their spine flexibility, demographic profile, and surgical options. The goal of corrective surgery for DLKS is to improve the sagittal and coronal spinal balance by correcting any spinopelvic malalignment. , $^{2,11,19}$ In the present series, the scoliosis correction rate was $66.4 \%$, evidenced by the significant improvement in postoperative spinopelvic parameters such as PI-LL and PT. The SVA and CVA were corrected after surgery and were well maintained throughout follow-up. In considering segmental spinal correction, Schwab et al. established a comprehensive spinal osteotomy classification, noting that a Grade 1 or Grade 2 osteotomy can provide $5^{\circ}-10^{\circ}$ of segmental correction. ${ }^{18}$ Bergin et al. ${ }^{3}$ also mentioned in their review that a Ponte osteotomy ${ }^{16}$ or Smith-Peterson osteotomy ${ }^{22}$ can provide $5-15^{\circ}$ in segmental correction. However, these kinds of spinal osteotomies can only work when the intervertebral disc has enough flexibility for correction. In contrast, a TLIF can provide a 3-column release that includes the disc, the facet joint, and the osteophytes that are connected to each vertebra. Additionally, an interbody fusion cage can play an important role in the support of the anterior column. Our CT analysis showed that the effect of IVR on TLIF was $10 \%$ level in the coronal plane and 
TABLE 5. Evaluating the effect of IVR using MPR CT images

\begin{tabular}{lccc}
\hline Parameter & PreO & PO & IVR Effect $^{*}$ \\
\hline SWA (range) & $15.4^{\circ}\left(5^{\circ}-26^{\circ}\right)$ & $4.5^{\circ}\left(0^{\circ}-12^{\circ}\right)$ & $10.9^{\circ}\left(2^{\circ}-21^{\circ}\right)$ \\
\hline SLA (range) & $5.6^{\circ}\left(-23^{\circ}\right.$ to $\left.22^{\circ}\right)$ & $12.5^{\circ}\left(5^{\circ}-22^{\circ}\right)$ & $6.8^{\circ}\left(-5^{\circ}\right.$ to $\left.29^{\circ}\right)$ \\
\hline
\end{tabular}

* Calculated using PreO and PO data.

$6.8^{\circ} /$ level in the sagittal plane. These data suggest that our surgical procedure can result in good coronal correction but limited sagittal correction. A TLIF can only yield an adequate 3-column release if it's performed using the posterior approach and an RR maneuver converts a scoliosis to a lordosis. Two studies have compared TLIF and anterior lumbar interbody fusion and indicated that there is no significant difference in the correction rate and clinical outcomes following the use of either technique in DLKS patients. ${ }^{914}$ Regarding segmental sagittal correction, TLIFs are limited because the insertion of larger intervertebral fusion cages is impossible given the small portal to disc space. Therefore, pedicle subtraction osteotomy ${ }^{13}$ or posterior vertebral resection ${ }^{23}$ is sometimes necessary to manage rigid kyphosis. Three-column osteotomies have a bigger potential risk of surgery-related complications, such as major bleeding, neurological deficits, and pseudarthrosis. ${ }^{15}$ However, surgical complications were rare in our series, which means that our procedure can be considered to be less invasive.

Using FBB films, ${ }^{6}$ we could evaluate the flexibility of the spinal curve in detail. If only simple bending films are used, the rigidity of the spine can be overestimated. In our series the preoperative PI-LL (FBB) was $14.1^{\circ}$ (range $-7^{\circ}$ to $29^{\circ}$ ), indicating a relatively flexible sagittal plane. The scoliotic lumbar curvature was $59.3^{\circ}$, with a $33 \%$ reduction in side bending films. Based on our data, a multilevel TLIF and RR are indicated for DLKS patients who have severe scoliosis and a relatively flexible sagittal deformity. A PI-LL (FBB) that is less than $25^{\circ}$ is thought to be a good indication for our technique.

There are some limitations to our study. We describe only a small number of cases without controls over a shortterm follow-up period. Future work should involve a longer follow-up period and a larger sample size.

\section{Conclusions}

In summary, a multilevel TLIF and RR method can provide improved coronal plane correction with limited sagittal plane correction. An FBB film is a good means of evaluation to select the appropriate surgical procedure. Our method is indicated for patients whose PI-LL (FBB) is less than $25^{\circ}$.

\section{References}

1. Aebi M: The adult scoliosis. Eur Spine J 14:925-948, 2005

2. Ames CP, Smith JS, Scheer JK, Bess S, Bederman SS, Deviren $\mathrm{V}$, et al: Impact of spinopelvic alignment on decision making in deformity surgery in adults: A review. J Neurosurg Spine 16:547-564, 2012

3. Bergin PF, O'Brien JR, Matteini LE, Yu WD, Kebashi KM:
The use of spinal osteotomy in the treatment of spinal deformity. Orthopedics 33:584-594, 2010

4. Bridwell KH, Baldus C, Berven S, Edwards C II, Glassman $\mathrm{S}$, Hamill C, et al: Changes in radiographic and clinical outcomes with primary treatment adult spinal deformity surgeries from two years to three- to five-years follow-up. Spine (Phila Pa 1976) 35:1849-1854, 2010

5. Charosky S, Guigui P, Blamoutier A, Roussouly P, Chopin D: Complications and risk factors of primary adult scoliosis surgery: a multicenter study of 306 patients. Spine (Phila Pa 1976) 37:693-700, 2012

6. Cheung KM, Luk KD: Prediction of correction of scoliosis with use of the fulcrum bending radiograph. J Bone Joint Surg Am 79:1144-1150, 1997

7. Cloward RB: The treatment of ruptured lumbar intervertebral discs by vertebral body fusion. I. Indications, operative technique, after care. J Neurosurg 10:154-168, 1953

8. Cotrel Y, Dubousset J: [A new technic for segmental spinal osteosynthesis using the posterior approach.] Rev Chir Orthop Repar Appar Mot 70:489-494, 1984 (Fr)

9. Crandall DG, Revella J: Transforaminal lumbar interbody fusion versus anterior lumbar interbody fusion as an adjunct to posterior instrumented correction of degenerative lumbar scoliosis: three year clinical and radiographic outcomes. Spine (Phila Pa 1976) 34:2126-2133, 2009

10. Dorward IG, Lenke LG, Bridwell KH, O'Leary PT, Stoker GE, Pahys JM, et al: Transforaminal versus anterior lumbar interbody fusion in long deformity constructs: a matched cohort analysis. Spine (Phila Pa 1976) 38:E755-E762, 2013

11. Glassman SD, Bridwell K, Dimar JR, Horton W, Berven S, Schwab F: The impact of positive sagittal balance in adult spinal deformity. Spine (Phila Pa 1976) 30:2024-2029, 2005

12. Grubb SA, Lipscomb HJ, Coonrad RW: Degenerative adult onset scoliosis. Spine (Phila Pa 1976) 13:241-245, 1988

13. Kim YJ, Bridwell KH, Lenke LG, Cheh G, Baldus C: Results of lumbar pedicle subtraction osteotomies for fixed sagittal imbalance: a minimum 5-year follow-up study. Spine (Phila Pa 1976) 32:2189-2197, 2007

14. Pateder DB, Kebaish KM, Cascio BM, Neubaeur P, Matusz DM, Kostuik JP: Posterior only versus combined anterior and posterior approaches to lumbar scoliosis in adults: a radiographic analysis. Spine (Phila Pa 1976) 32:1551-1554, 2007

15. Ploumis A, Transfledt EE, Denis F: Degenerative lumbar scoliosis associated with spinal stenosis. Spine J 7:428-436, 2007

16. Ponte A, Vero B, Sicicardi G: Surgical treatment of Scheuermann's hyperkyphosis, in Winter R (ed): Progress in Spinal Pathology: Kyphosis. Bologna, Italy: Aulo Gaggi, 1984, pp 75-81, 1984

17. Sansur CA, Smith JS, Coe JD, Glassman SD, Berven SH, Polly DW Jr, et al: Scoliosis Research Society morbidity and mortality of adult scoliosis surgery. Spine (Phila Pa 1976) 36:E593-E597, 2011

18. Schwab F, Blondel B, Chay E, Demakakos J, Lenke L, Tropiano P, et al: The comprehensive anatomical spinal osteotomy classification. Neurosurgery 74:112-120, 2014

19. Schwab F, Lafage V, Patel A, Farcy JP: Sagittal plane considerations and the pelvis in the adult patient. Spine (Phila Pa 1976) 34:1828-1833, 2009

20. Schwab F, Ungar B, Blondel B, Buchowski J, Coe J, Deinlein D, et al: Scoliosis Research Society-Schwab adult spinal deformity classification: a validation study. Spine (Phila Pa 1976) 37:1077-1082, 2012

21. Simmons ED: Surgical treatment of patients with lumbar spinal stenosis with associated scoliosis. Clin Orthop Relat Res (384):45-53, 2001

22. Smith-Petersen MN, Larson CB, Aufranc OE: Osteotomy of the spine for correction of flexion deformity in rheumatoid arthritis. Clin Orthop Relat Res 66:6-9, 1969

23. Suk SI, Chung ER, Lee SM, Lee JH, Kim SS, Kim JH: Pos- 
terior vertebral column resection in fixed lumbosacral deformity. Spine (Phila Pa 1976) 30:E703-E710, 2005

24. Takahashi S, Delécrin J, Passuti N: Surgical treatment of idiopathic scoliosis in adults: an age-related analysis of outcome. Spine (Phila Pa 1976) 27:1742-1748, 2002

25. Taneichi H, Suda K, Kajino T, Matsumura A, Moridaira H, Kaneda K: Unilateral transforaminal lumbar interbody fusion and bilateral anterior-column fixation with two Brantigan I/F cages per level: clinical outcomes during a minimum 2-year follow-up period. J Neurosurg Spine 4:198-205, 2006

26. Yagi M, King AB, Boachie-Adjei O: Characterization of osteopenia/osteoporosis in adult scoliosis: does bone density affect surgical outcome? Spine (Phila Pa 1976) 36:1652-1657, 2011

27. Velis KP, Healey JH, Schneider R: Osteoporosis in unstable adult scoliosis. Clin Orthop Relat Res (237):132-141, 1988

\section{Disclosures}

The authors report no conflict of interest concerning the materi- als or methods used in this study or the findings specified in this paper.

\section{Author Contributions}

Conception and design: Matsumura. Acquisition of data: Matsumura, Namikawa, Kato, Ozaki, Hori. Analysis and interpretation of data: Matsumura. Drafting the article: Matsumura. Critically revising the article: Matsumura, Nakamura. Reviewed submitted version of manuscript: Matsumura. Approved the final version of the manuscript on behalf of all authors: Matsumura. Statistical analysis: Matsumura. Administrative/technical/material support: Matsumura. Study supervision: Namikawa, Kato, Hidaka, Nakamura.

\section{Correspondence}

Akira Matsumura, Department of Orthopaedic Surgery, Osaka City General Hospital, 2-13-22 Miyakojimahondori, Miyakojimaku, Osaka 534-0021, Japan. email: amatsumura@med.osaka-cu. ac.jp. 